\title{
Strategies for implementing evidence-based practices in routine mental health settings
}

The term 'evidence-based medicine' was coined in 1990. Since then, the systematic use of scientific evidence in clinical decision-making has expanded. ${ }^{1}$ The evidence-based medicine movement inspired parallel developments in mental health. Administrators, clinicians, advocates and researchers generally agree that they are obligated to provide the most effective mental health treatments. Implementing evidence-based practices in routine treatment settings is a crucial part of this..$^{2-5}$

The key question is: how do we implement evidence-based practices? Routine mental health settings are generally deficient in evidence-based practices. ${ }^{2-5}$ To redress this, we must understand broad-scale implementation in diverse treatment systems. Working with state mental health systems and researchers throughout the United States, we have been engaged in a multi-state demonstration, the National EvidenceBased Practices Project. ${ }^{6-9}$ We used several sources to understand implementation: literature on changing healthcare practices; focus groups and interviews with stakeholders; the experience of advocacy groups, and the collective experiences of mental health researchers. ${ }^{9}$ This editorial summarises findings from these sources and describes the US National Evidence-Based Practices Project.

\section{Implementing evidence-based mental health programmes}

PRACTICE IMPLEMENTATION LITERATURE

The practice implementation literature agrees on several points. First, education alone is ineffective at changing health care practices. ${ }^{10}$ Changing complex programmes requires more extensive interventions than education or training. Among the strategies involved are enhancing motivation, providing adequate resources, increasing skill development and removing environmental constraints. ${ }^{11}$ Second, change occurs over time. Implementation strategies can be divided into three stages: a) motivational or educational interventions to prepare for change; b) enabling or skill building interventions to enact a new practice, and c) reinforcing, structural or financing interventions to sustain change. ${ }^{12}$ Third, greater effort and involvement by stakeholders increases success. ${ }^{13}$ Multifaceted changes that involve all stakeholders, rearrange daily workflow to support new practices and are reinforced by financing and regulatory strategies are more likely to succeed than those focussing exclusively on changing practitioners' behaviour. Finally, programme implementation is most likely to be successful when it matches the values, needs and concerns of practitioners. ${ }^{14}$

\section{MENTAL HEALTH ADMINISTRATORS}

Mental health administrators identify three essential elements for implementing new programmes: clear guidelines, effective training materials and consistent incentives. ${ }^{9}$ Guidelines need to be more than a practice description. Administrators need specific advice on issues such as structural elements, workforce requirements and process and outcome measures. Due to high staff turnover and the limits of professional training, it is important to train new workers fully. To create uniform and high-quality skills, standardised training guidelines and ready access to current treatment information are needed.
Finally, procedural reinforcements, such as regulations, finances, contracts, credentials, paperwork and outcome assessments need to be consistently aligned.

\section{MENTAL HEALTH PRACTITIONERS}

The reluctance of workers to adopt new practices is often cited as a barrier to change. ${ }^{9}$ In general, practitioners prefer to learn skills consistent with their current values, practices and professional identities in areas they identify as needing new approaches. For example, practitioners may be more comfortable learning cognitive behavioural skills than family interventions if they perceive the first to be closer to their current practices. Many practitioners express interest in learning dual diagnosis or trauma interventions because these are areas where they recognise a need for change.

Practitioners learn new skills in different ways. They variously prefer workbooks, manuals, training videos, computerised self-learning programmes or discussions with experts or peers. Despite variation in styles of learning, practitioners agree that training is more effective over time (months and years) with on-going opportunities to try new behaviours and discuss their work with peers or supervisors. This accords with research on the ineffectiveness of educational sessions alone. ${ }^{10}$

\section{MENTAL HEALTH ADVOCATES}

Advocates, particularly the National Alliance for the Mentally Ill in the United States, have increased funding for research and clinical services and disseminated evidence-based practices. The push for assertive community treatment teams is an example. ${ }^{15-16}$ The most effective advocates are private industry and guild organisations, where increasing profit may be a greater motivation than the promotion of evidence-based practices. Nevertheless, grassroots advocacy is increasingly influential and can facilitate new practices being adopted locally.

\section{MENTAL HEALTH RESEARCHERS}

Researchers studying multi-site implementation of evidencebased treatments identify several critical factors. These include involving all stakeholder groups, particularly administrators, during preliminary consensus-building activities; jobshadowing visits to allow practitioners to observe well functioning programmes and ask questions; longitudinal clinical training with feedback and support; follow-up consultation with an expert about process and outcomes, and structural, organisational and financial changes to sustain new programmes. ${ }^{17-18}$

\section{The National Evidence-Based Practices Project}

We know a considerable amount about changing mental health practices, but large scale, country-wide implementation is rare. The National Evidence-based Practices Project aims to implement effective mental health practices in diverse settings. The project has three phases. Phase 1 involves developing structured resources (toolkits) for consultation, training and implementation in six areas of evidence-based practice (illness management and recovery; family psychoeducation; medication management; supported employment; assertive community treatment, and integrated dual disorders treatment). 
The materials draw on the implementation strategies summarised above. Phase 2 involves an extensive field trial of the toolkits and implementation materials. Phase 3 is a national effort to implement evidence-based practices throughout the United States. $^{6-9}$

The toolkits include materials specifically designed for, co-authored by and reviewed by five stakeholder groups: users of mental health services; their families; practitioners; programme leaders, and policy makers. The materials address positive, active and educational roles that these groups can play in promoting successful implementation. Materials are presented using workbooks, training videos, pamphlets, didactic talks and websites. Practitioners and teams are encouraged to use the materials in ways that best facilitate their learning. The toolkits are intended for use in conjunction with a trainer or consultant who is knowledgeable about the practice and experienced in training and sustained consultation. For Phases 2 and 3 , states are expected to develop training and implementation institutes, which may take different forms, but always include trainers and consultants dedicated to helping local people implement evidence-based practices. ${ }^{7}$

The Phase 2 field trial, being conducted between 2002 and 2004, will provide an opportunity to study implementation in approximately 55 routine mental health centres. Quality improvement specialists in each state will examine the baseline characteristics of organisations; the barriers encountered and strategies used over time for motivating and sustaining a new practice; the success or failure of implementation, and client outcomes. In addition, systematic feedback will be used to improve toolkits, training and consultation for Phase 3.

In summary, there are various strategies for implementing complex, evidence-based mental health practices in routine treatment settings. Findings from the multi-state evaluation of evidence-based practice implementation will inform our approach to new practices in mental health settings.

A fuller description of the National Evidence-based Practices Project and other ideas outlined in this piece is available in: Torrey WC, Drake RE, Dixon L et al. Implementing evidence-based practices for persons with severe mental illnesses. Psychiatric Services 2001; 52:45-50.
ROBERT E DRAKE, MD PhD

Professor of Psychiatry

WILLIAM C TORREY, MD

Associate Professor of Psychiatry

GREGORY J MCHUGO, PhD

Associate Professor of Community and Family Medicine All authors at Dartmouth Medical School, New Hampshire, USA

1 Guyatt G, Rennie D (eds). Users' guides to the medical literature. Chicago: American Medical Association, 2002

2 Institute of Medicine. Building a bridge to cross the chasm. Joint Commission Perspective 2001; 21: 1-3

3 National Advisory Mental Health Council's Clinical Treatment and Services Research Workgroup. Bridging science and service. National Institutes of Health, 1999 .

4 National Alliance for the Mentally Ill Board of Directors. Strategic Plan for 2001-2003. Arlington: National Alliance for the Mentally Ill, 2001.

5 Center for Mental Health Services. Mental Health. a report of the surgeon general. Rockville, MD: Center for Mental Health Services, 1999.

6 Drake RE, Goldman HH, Leff HS et al. Implementing evidence-based practices in routine mental health service settings. Psychiatric Services 2001; 52: 179-82.

7 Goldman HH, Ganju V, Drake RE et al. Policy implications for implementing evidence-based practices. Psychiatric Services 2001; 52: 1591-7.

8 Mueser KT, Torrey WC, Lynde D et al. Implementing evidence-based practices for people with severe mental illness. Behavior Modification 2003, in press.

9 Torrey WC, Drake RE, Dixon L et al. Implementing evidence-based practices for persons with severe mental illnesses. Psychiatric Services 2001; 52: 45-50.

10 Davis DA, Thomson MA, Oxman AD. Changing physician performance: A systematic review of the effect of continuing medical education strategies. Journal of the American Medical Association 1995; 274: 700-5.

11 Fishbein M. Developing effective behavioral change interventions: Some lessons learned from behavioral research. In: Backer TE, David SL, Soucy $\mathrm{G}$ (eds). Reviewing the behavioral science knowledge based on technology transfer. NIDA Research Monograph 155. Rockville: National Institute on Drug Abuse, 1995.

12 Green L, Kreuter M, Deeds S. Health Education Planning: A Diagnostic Approach. Palo Alto: Mavfield, 1980.

13 Schulberg HC, Katon W, Simon GE. Treating major depression in primary care practice: An update of the Agency for Health Care Policy and Research practice guidelines. Archives of General Psychiatry 1998; 55: 1121-7.

14 Grimshaw JM, Russell IT. Effect of clinical guidelines of medical practice: A systematic review of rigorous evaluations. Lancet 1993; 342: 1317-22.

15 Allness DJ, Knoedler WH. The PACT model of community-based treatment for persons with severe and persistent mental illness: A manual for PACT. Arlington: National Alliance for the Mentally Ill, 1999.

16 Phillips SD, Burns BJ, Edgar ER et al. Moving assertive community treatment into standard practice. Psychiatric Services 2001; 52: 771-9.

17 Becker DR, Torrey WC, Toscano R et al. Building recovery-oriented services: Lessons from implementing IPS in community mental health centers. Psychiatric Rehabilitation Journal 1998; 22: 51-4.

18 Liberman RP, Eckman TA. Dissemination of skills training modules of psychiatric facilities: Overcoming obstacles to the utilisation of a rehabilitation innovation. British Journal of Psychiatry 1989; 155: 117-22. 